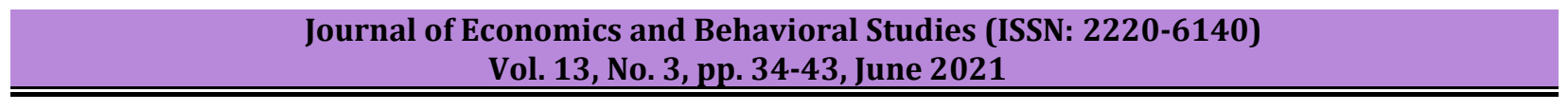

\title{
Self-Destructive Work Behavior Management for Socio-Economic Emancipation: A Classic Case of Saving One from Oneself
}

\author{
Miebi Ugwuzor \\ Department of Management, Niger Delta University, Wilberforce Island, Yenagoa, Bayelsa State, Nigeria \\ ebiugwuzor@yahoo.com
}

\begin{abstract}
Africa is amply endowed with diverse dimensions of resources as well as having a rich cultural heritage with great potentials for economic growth and development. It is also worthy of mention that the resourceful capacities of Africans in the diaspora in all spheres of life have contributed immensely to the development of other continents of the world. Despite these great progressive potentials, a large percentage of African States are in obvious and dire need of sustainable socio-economic emancipation. This glaring need to identify the key challenges and propose solutions necessitated this study. This study is conceptual and examined self-destructive behaviors at multiple levels using theoretical underpinnings from the Human survival and the self-destruction paradox as well as the dialectical behavioral therapy. This Paper identified several ingrained sources of self-destructive work behaviors in contemporary public sector workplaces in Africa which contribute to the socio-economic challenges. This work highlights that these obnoxious, selfdestructive work behaviors seem highly inimical to management praxis. The behaviors seem capable of contending against the aggregate fight for sustainable socio-economic emancipation of the Continent. Deliberate self-salvation was opined here to steer away behaviors, especially in workplaces, from this current path of self-destruction. Novel Actionable thoughts were suggested to stem this unfavorable tide and push for a generation of operational work behaviors as well as an ethical renaissance in management praxis for the emergence of archetypes completely devoid of any anti-progress tendencies.
\end{abstract}

\section{Keywords: Africa, Behavior, Development, Management, Self-Destructive.}

\section{Introduction}

The Pre-Partition Era of Africa saw gallant people who through resilience, doggedness and ingenuity were, able to forge tools and apply simple operations and technologies to excel in all areas of human endeavors pertaining to their worldview at that time. The African Continent can boast of a strong spirit of resilience that has triggered initiatives that have spurred resourcefulness and intellectual accomplishments so far in her history. The African continent has been credited with the notable status as a cradle of civilization and her very bright prospects, gazetted in the annals of history. The Partition Era came with its pains and gains and although the African States have their political emancipation, the strife for socio-economic emancipation rages on. This struggle for the socio-economic emancipation of Africa as a whole has been a long and tortuous one. Concerted and continuous candid efforts have been and are still being made to harness her potentials and for her to take her pride of place among the comity of Continents (Ejiaku 2014; Seck, Agboh-Noameshie, Diagne \& Bamba, 2013). The Organization of Africa Unity, which was established in 1963 and metamorphosed into the African Union in 2002.

Through programs such as the New Partnership for Africa's Development among others as well as other individual and corporate entities with Pan-Africanist ideologies have been key actors in this struggle. Nevertheless, the apparent general socio-economic outlook still shows glaring gaps to be filled. The United Nations General Assembly in 2015 designed a collection of seventeen goals to chart the course of a better future for the nations of the world. These Sustainable Development Goals (SDGs), as part of the United Nations 2030 Agenda resolutions, are intended to ensure that at the targeted year of 2030, there will be no poverty, zero hunger, good health and wellbeing, quality education, gender equality, clean water and sanitation, affordable and clean energy, decent work and economic growth, Industry, innovation and infrastructure, reduced inequality, sustainable cities and communities, responsible consumption and production, climate action, care for life below water and life on land, peace, justice, strong institutions as well as a partnership for the goals( United Nations, 2015). There have been several previous laudable long-term plans and timelines of such nature as the SDGs. 
However, Ndizera and Muzee (2018) identified limited finances, lack of ownership, lack, of political will, diverse and sometimes conflicting interests as well as lack of ideological backup as some of the challenges that may prevent such long term plans from achieving significant results in Africa. Currently, the predominant socio-economic identity of the African continent still seems to show high levels of poverty as well as similar gross shortcomings indicative of extreme lack in the Strategic Development Goals of the United Nations and reeks of many negative attributes with attendant reflections of despair and hopelessness. The African continent as the second most populous continent of the world is home to many potentials and resources. Rather than reflecting the status of a giant, there seems to be a reflection of diminutive attributes which do not put her in proper perspective. Extant literature is in line with this observation (Besada, 2017; Dauda, Ahmad, \& Keling, 2019; Hanson, 2017). Many political leaders and managers of productive sectors of many private and public workplaces are highly trained; possess high capacity and capabilities as well as intellectual skill sets and prowess to handle challenges of their work demands that will put the best foot of the continent forward. However, certain extraneous factors such as corruption, highhandedness, dictatorial rule, luxurious living, fraudulent self-preservation and lack of transparency have been attributed to the somewhat abysmal performance (Amadi \& Ekekwe, 2014; Mlambo, Mubecua, Mpanza \& Mlambo, 2019; Odemba, 2012).

Also, the observable abysmal levels of economic growth and the somewhat arrested development in Africa have been attributed to poor economic policies. In line with this thought, scholars have suggested appropriate policies and structural economic transformation, improved policy coordination as well as harmonized policy initiatives of regional groups as a veritable solution to the apparent quagmire of the continents development (Atta-Mensah, Tang \& Shaw, 2017; Zerihun, Breitenbach \& Kemegue, 2015). It has been argued that the intellectual capacity and natural resources of the continent have nothing to do with her performance and as noted by Aloko \& Usman (2018) there seems to be an ironic reversal in human history where there exists no concrete relationship between available human/natural resources and the state of development. Despite the foregoing, this work believes that self-destructive work behaviors which seem not to have been previously captured in the extant literature are a major impediment to economic emancipation and may have emanated from certain socio-ethical foundations. Ethics, a series of rules and principles, is often used to decide what behaviors are right, good and proper and defines how things should work according to rules of conduct, prescribed to an individual by an external source such as a profession, business, and social system (Wiid, Cant \& Niekerk, 2013). As succinctly put by Singer (2020), ethics are otherwise known as moral philosophy is concerned with what is morally good and bad and morally right and wrong.

In other words, the cause of someone's or something's challenges may not be far. Thus, within the context of this work and without necessarily going into the vector host analogy of the axiom, this work assumes that there is a strong need for a critical introspective look at contemporary work behaviors as well as the socially prescribed and imposed ethical influences on behaviors as well as the fundamental building blocks guiding workplace behaviors. Workplace behaviors exhibited by employees go a long way to make or mar their expected productive outcomes (Ugwuzor, 2018). It has been noted that each productive workplace is a microcosm of the productive fabric of the economy of the nation (Akugri, Bagah \& Wulifan, 2015; Muritala, Taiwo, Awolaja \& Bako, 2012). It is assumed here that the economic outputs of each nation in Africa will have socio-economic implications for and the performance of the Gross Domestic Products of the Continent. The public service was the primary focus of this work and the behaviors of employees in public sector organizations, who are critical key drivers of economies, were examined to gain profound insights into selfdestructive behaviors in work environmental contexts. This was born out of the need to explore avenues fundamental to the achievement of the much-desired socio-economic emancipation. This work is a deliberate attempt at self-salvation by spurring novel self-therapeutic actionable thoughts and consciousness which will eliminate socio-ethical flaws within the behavioral ecosystem and generate progressive workplace behaviors.

\section{Theoretical Underpinning}

This work was highly interested in certain underlying somewhat self-destructive work behaviors of management and staff of organizations that have adversely affected management praxis in firms in the landscape of the African public productive sectors. Behavior that a person perpetrates against himself/herself with the tendency to cause potential or actual harm is said to be Self-destructive behavior. This may imply that one may not realize that one could sometimes be one's own worst enemy. One theoretical underpinning 
of this work was hinged on Walters (1999) Integrated Theoretical Model of Human Survival and the SelfDestruction Paradox. This model draws strength from evolutionary biology, existentialism, developmental psychology, and social learning theory. To the proponent of this model, self-destructive behavior is a function of how an individual psychologically construes survival and copes with perceptions of isolation and separation from the environment. The paradox of self-destructive behavior in organisms is driven by the need for self-preservation. Walters (1999), believes that self-destruction stems from a person's efforts to survive psychologically and resolve the subject-object duality, even when this places their physical well-being at risk. Ikeda (2016) has observed that people make self-destructive decisions that bring small immediate satisfaction but have adverse effects on the individual's future and classified self-harmful behaviors to include under-saving, over-borrowing, credit-card bankruptcy, overeating, smoking, drug abuse, and gambling addiction.

The Walters (1999) Integrated Theoretical Model has been applied to several forms of self-destructive behavior to include anorexia nervosa, substance abuse, pathological gambling and suicide. It is notable that all of the aforementioned range from self-harm to suicide. The behaviors of key actors in the productive sectors of the African economy were a major concern of this work. The observable general work behaviors exhibited by many employees in work settings, irrespective of the work cadre, seem to portray varying levels of unconscious and somewhat latent self-destructive tendencies akin to parasuicide and even suicide itself. The acts carried out, sometimes, with impunity may not only jeopardize and eventually kill the career of the perpetrator but also put the health and life of the organization in jeopardy with an attendant negative effect on the national and continental economies. The perpetrators tend to exhibit the behaviors usually for shortrun primordial benefits. All the behaviors exhibited through self-destructive may also be a way to cope with the pressures of life for example a person may perpetrate fraud or take a bribe to cope with the personal desire to acquire wealth or meet societal expectations even though the person knows that the penalty of being caught is sack and prosecution.

This work also aligns with Dialectical behavioral therapy (DBT) which is based upon the biosocial theory of Borderline Personality Disorder. DBT is the first therapy that has been experimentally demonstrated to be generally effective in treating borderline personality disorder (BPD). It is in the light of the for egoing that this work explored self-destructive work behaviors within the realm of Psychological disorders. Butcher, Mineka, \& Hooley (2007) have defined a psychological disorder as an ongoing dysfunctional pattern of thought, emotion, and behavior that causes significant distress, and that is considered deviant in that person's culture or society. Linehan (1993) opines that Borderline personality disorder is primarily a disorder of emotional dysregulation and emerges from transactions between individuals with biological vulnerabilities and specific environmental influences. As a type of Cognitive Behavioural Therapy, DBT attempts to identify and alter faulty thinking patterns to achieve desired behavioral changes. There is evidence that DBT can be useful in treating mood disorders, suicidal ideation, and change in behavioral patterns such as self-harm as well as other self-destructive behaviors. It is worthy of mention here that Cognitive behavior therapy (CBT) helps to identify and change views of oneself, the world, and the future.

In other words, with the aid of CBT, one can become aware of one's unhealthy ways of thinking and learn new behavioral patterns. Any behavior causing harm to the individual, regardless of the intention, aim, awareness of their negative consequences, time perspective, the object of harm as well as whether it is a direct or indirect threat can be referred to as self-destructive behaviors (Tsirigotis, 2018). Self-destructive behavior such as drug addiction has been classified as a chronic health condition and quitting usually takes more than good intentions or a strong will (NIDA, 2018). Self-destructive work behaviors, apart from the self-harming, self-sabotaging and dangerous effects on the personal life of the perpetrator, jeopardize the health and life of the perpetrator work career, an organization where the individual works as well as other beneficiaries of the work behavior of any individual employee such as the society and economy. Persons that engage in selfdestructive work behaviors, whether consciously or unconsciously may have genuine intentions to come out clean but may be unable to do so by themselves. Thus, this work, in aligning with Dialectical behavioral therapy (DBT), identifies with the need for deliberate diagnosis and therapy as well as the development of other useful models to care for and save persons with self-destructive work behavioral parasuicidal and suicidal tendencies. This is an attempt at self-salvation. 
Self-Destructive Work Behavior Management: The model being prescribed in this work for SelfDestructive work behavior management is a multi-level simultaneous self-diagnosis and therapy. With the aid of CBT, one can become aware of one's unhealthy ways of thinking and learn new behavioral patterns. Namely, the individual- level, the corporate- level and the societal- level. The intertwined relationship between the levels is also emphasized to give a holistic picture of the various sources of the levels of SelfDestructive Work Behaviors for effective Management. There is a popular African axiom which states that "the ant destroying the kola nut lives within it". When self-destructive behaviors are exhibited in the workplace to the extent that the work careers of the individual perpetrator and the health and survival of the firm a perpetrator works for are at risk, it translates to Self-Destructive Work Behavior. In many African societies, ethical values tend to guide the behaviors of members and these socio-ethical values may also be brought to workplaces of the productive ecosystems of nations. The societies, which are organized and functioning human communities, have evolved ethical systems which include ethical values, principles and rules which are intended to guide social and moral behavior Gyekye (2011). Firms are usually established for well-defined purposes or goals. Employees who are engaged to help the firms in achieving the said purposes and/or goals may also do so for job security and get to the peak of their personal work careers. The commonsensical expectation is that the employees will work in line with the set purposes or goals. Many employees may honestly want to put up behaviors that may sync with the direction of the organization.

However, more often than not, they tend to exhibit certain behaviors totally inimical to the health of the organization and the detriment of their work careers. These behaviors that employees exhibit consciously or unconsciously, which jeopardize the career of the perpetrator of the behavior and that are at logger's heads with the goals as well as long term health and survival of the perpetrator's workplace are said to be selfdestructive work behaviors. Such destructive work behaviors not only expose the individual career to the danger of termination but also endanger the health and longevity of the organization they work for. It is no gainsaying that the health and longevity of an organization depend on the work behaviors of its employees. The management of such behaviors in the workplace may involve case investigations as well as setting up therapeutic behavioral intervention strategies to curb the behaviors, noting the element of self-diagnosis and therapy. Diagnosis is often seen as a primary tool for the work of medicine as they tend to identify, categorize and classify illnesses, disorders and other health conditions. In that light diagnosis is seen as the process of determining the nature of a disease or disorder and distinguishing it from other possible conditions (Rakel, 2018). Diagnosis is useful in providing necessary information on the meanings that people attach to the feelings and behaviors they are experiencing, as well as societally sanctioned explanations to all concerned parties about problematic symptoms (Wykes and Callard, 2010). However, Jutel (2019) sees diagnosis as a profoundly social act, which reflects society, its values and how it makes sense of illness and disease.

Without necessarily going into the various psychological and even psychiatric attributions and associations of self-destructive behaviors in persons, this work strongly believes that the actions and/or inactions of many employees and the current predominant work praxis in many work settings within the African productive ecosystems depict various levels in the continuum of self-destruction which range from traces of parasuicide to suicide itself. The behaviors of the perpetrators do not only seem subconsciously or unconsciously driven but also helplessly deliberate. For example, apart from some levels of impulsivity, which seem to be subconsciously driven, perpetrators may tend to turn deaf ears and seem to choose the death of their careers instead of quitting such behaviors. Impulsivity, an enduring tendency to react hastily rather than deliberately is based on immediate gratification as opposed to future-oriented problem solving (Barratt, 1994; Herpertz, Sass \& Favazza, 1997). It may be argued that the current highly volatile and unstable business environment calls for quick actions and decisions and no doubt some of the consequential outcomes may turn out beneficial, this work categorizes the construct of impulsivity in the dysfunctional sense, more especially so, if impulsivity is habitual with an undertone of escalation of commitment or ulterior motives of the decisionmaker. Impulsivity has been found to be related to a wide range of maladaptive self-destructive behaviors, such as kleptomania, pyromania, intermittent explosiveness, substance abuse, antisocial behavior, bulimia, conduct disorder and self-mutilation (Barratt, 1994). 


\section{Sources of Employees' Self-Destructive Work Behavior}

As part of the case investigation of self-destructive work behavior, it becomes imperative to identify and trace the sources of self-destructive work behaviors of employees.

Individual-Level Sources: The individual-level sources of self-destructive work behavior may originate from the personality traits, habits, personal attitudes archetypes and/or tendencies of the individual employee which may $a b$ initio be skewed in the direction of self-destruction. In other words, the individual may have certain underlying character traits, habits and/or tendencies that are already detrimental and antiprogressive to the individual's wellbeing. If these traits, habits and tendencies when brought to the workplace interfere with smooth operations and behavioral expectations at work, then it gives rise to the employee's self-destructive work behavior. Some personality traits, habits and/or tendencies may include laziness, greed, pride and avarice, excessive personal quest for power, high-handedness .narcissism and selfishness to mention a few. Individual-level sources of self-destructive work behavior may also stem from social influences from the family, socio-ethical heritage of the society and methods adopted to run corporate institutional processes, the technology adopted as well as the social systems within the workplace.

If the behaviors are not condoned by the workplace and society then, individuals will likely make better efforts at doing away with such behaviors. It is interesting to note that the exhibition of these self-destructive work behaviors is not limited to the rank and file employees alone. The management staff at the various levels of management may also be culpable. These self-destructive behaviors exhibited by management staff may also tend to have ripple effects on the work behaviors of their subordinate employees and, of course, on the organization as a whole. Still drawing from the African axiom that the ant that destroys a kola nut lives inside it, it is apparent that what 'lives' within the individual or is part of the individual is destroying him/her. Put differently, an employee's self-destructive work behavior may not be too far from the highlighted personal sources. In other words, the source of an individual's behavioral phenomenon exhibited may just lie within the individuals and manifests in the way they do things.

The Individual-Level Self-Diagnosis and Therapy: In this model, individuals are made aware of the signs and symptoms of self-destructive work behaviors. When honestly self-assessed, the individual could understand what could amount to a self-description of self-destructive work behavior as well as their patterns of behavior. Identifying self-destructive work behaviors could be a challenge especially when it comes to recognizing one's behavior. It is made worse by self-deceit as one may not want to admit an identified work behavior as self-destructive. Identifying self-destructive work behaviors may even be easier to spot when looking at someone else's work behavior. However, beaming the same searchlight on oneself may expose self-destructive work patterns. Self-awareness could also be gained through education and information on what constitutes self-destructive work behavior, the predisposing factors as well as the harmful effects of such behaviors on themselves and others. Some symptoms of self-destructive behaviors that may transcend to the workplace include laziness, lack of motivation, lack of energy, self-aggrandizement frequent interpersonal friction with colleagues, always blaming ones failure on other people or external forces, procrastination as well as lack of time-consciousness in terms of punctuality and keeping to deadlines, haphazard ways of planning, amongst others.

The basic therapeutic behavioral intervention should answer the question of how the individual could be saved from that which is part of him/her. For persons who have identified self-destructive work patterns in themselves, the key step to positive change is the will to change and the strategies to adopt. If one is honest to oneself, one should be able to talk out oneself from the self-destructive work behavior and not allow such behavior to go on unchecked. Personal therapy may include critical self-examination, values redefinition and reorientation devoid of self-destructive and anti-progress tendencies. An individual may have an intrinsic drive to work which will make such a person have good reasons independent of any external motivating force. Also, with a reasonable yardstick for standard self-performance appraisal, one should hold oneself accountable for performance lapses after a careful self-appraisal shows lapses are self-inflicted. If the identified lapse in performance is caused by physical factors such as hunger, lack of sleep, ill health, overindulging in other activities other than work itself, personal efforts should be made to address the issues. One may also seek more interesting ways of doing work and think of something to like in one's job or any 
other job one would want to do. Self-destructive work behaviors may be identified by an individual perpetrator or a concerned supervisor or colleague.

By submitting oneself to external help, issues of punctuality, time consciousness and interpersonal work relationship could be addressed. Help may also come to an individual by way of counseling provided by the organization through a unit for that purpose within the organization or external firms with a support system that will help eliminate such behaviors. Couching and mentoring of individual employees on personal work ethics and character molding should be, put in proper perspective to address Self -destructive work behaviors. Since the behavior did not start overnight, time and determination are essential for positive change to occur. To prevent a relapse, the individual should openly advocate against such self-destructive behaviors. New behaviors could be learned that will make a perpetrator resourceful, insightful, compassionate and selfless.

Corporate-Level Sources: It is important to clarify at this point that the firm is a corporate entity and is regarded here as a 'person' which can have identifiable 'self-destructive behaviors' A corporate entity's selfdestructive behavior is made manifest when a firm's culture, structure, policies and processes are such that they seem inimical its own purposes and goals and adjudged detrimental to its own health and survival. Some self-destructive work behaviors of employees could stem from their firms ' self-destructive behaviors'. Based on the lapses and inadequacies of the corporate structure and culture, for instance, individuals may tend to begin to exhibit certain self-destructive work behaviors. For example, if a firm's processes are not transparent and there are no laid down structures for accountability and probity, individual employees, especially those who by their personal sources are predisposed to some already underlying self-destructive behaviors, may have room to indulge in fraud, high handedness as well as corruption of various forms. Corruption in this case is not only seen as a situation where persons unduly enrich themselves and personally gain from certain institutional processes.

But includes individual activities that negate the general good of the generality of the populace. Some Firms seem to have perceived distorted rules on the distribution of organizational favors and punishments. This may picture the firm as one with corporate cultures and structures that allow for favoritism. Also, some firms may seem to have perceived a distorted meaning of teamwork. In this case, one may observe many ingroup/out-group formations within and between teams within the firm. Corporate culture should foster an atmosphere where everybody thinks of the good of their fellow employees, the betterment of the whole firm and, perhaps, how the success of their firm could add value to the national Gross Domestic Product. A toxic work environment stifles the employees, organizational citizenship behaviors and creates room for bickering and rancor. When a work environment is toxic and firms' processes and procedures do not seem transparent, de-emphasize accountability and probity, to mention a few, such firms are exhibiting corporate selfdestructive behaviors from which employees' self-destructive behaviors may emanate.

The Corporate Level Self-Diagnosis and Therapy: The corporate level diagnosis of destructive behaviors could come as a managerial and leadership responsibility to organizations. The ultimate desire of any corporate diagnosis of destructive work behavior is for performance improvements in the Firms. The contemporary managers can right the wrong of previous 'ancestors' noting that the contemporary managers are ancestors to the future generations. Apart from the expectation that firms should have a code of ethical work behaviors for all employees that will serve as the work behavioral compass to guide workplace behaviors in line with the particular firm's goals and purposes, the corporate culture and structure should have tell-tale mechanisms to identify self-destructive work behaviors if corporate structures, cultures and processes are distorted and are not transparent nor their strategies result-driven, individuals will tend to begin to exhibit tendencies.

Such as greed avarice, wealth accumulation, biased and faulty decisions, conflict of interest, ulterior motives, high sense of entitlement. The outcome of such tendencies is capable of truncating or even eliminating the future and posterity will not judge contemporary managers right if the current situation goes on unabated. Suffice it to say that there are some contextual interpretations of Afrocentric thoughts which may have implications for socio-ethical workplace behaviors. For example the maxim in the African contextual thought that one should be ones brother's keeper. This may not be wrong on its own. However, 'brotherhood' has 
been interpreted in a sense that selectively favors a few in-group members of a sect to the detriment of the generality. There is also the sense of entitlement mentality as individuals may have a sense of entitlement that their brother or close associate is at the helm of affairs so they are entitled to certain favors.

Also, persons from host communities of firms believe that they are the 'land lords' of the firms and are thus entitled to certain rights and privileges without necessarily meriting them. A corporate therapy direction will be to have reorientation programs that emphasize 'humanhood' as a way of thinking of the collective progress of humanity and the meaning expanded to cover persons of the entire humanity so that all goodwill will be done to all in the same way rather than the already misconstrued 'brotherhood'. There is also an obvious and dire need to re-gig the management praxis in workplaces in a way that de-emphasizes unclear and unfavorable corporate cultures, structures and policies on the distribution of organizational favors as well as policy summersaults and canonical politics among other corporate entity's self -destructive behaviors which may have very serious socio-ethical implications in workplaces.

Societal-Level Sources: When the socio-ethical norms of society seem inimical to its growth and development such norms or acceptable practices are self-destructive and must be changed. Suffice it to say that Society is being personified here to re-emphasize the intertwined relationship between the individual, firm and society. Based on some socio-ethical influences and societal expectations some employees, sometimes unbeknownst to them, tend to exhibit self-destructive work behaviors. African ethics is used to refer both to the moral beliefs and presuppositions of the sub-Saharan African people and the philosophical clarification and interpretation of those beliefs and presuppositions (Gyekye, 2011). Without necessarily going into the controversy of what constitutes sub-Saharan Africa, it is imperative to state that ethics have played important roles in shaping how societies are run and how citizens contribute to the general wellbeing of their societies. The African environmental settings and societal makeup have a very rich cultural heritage that has been traditionally handed down from generation to generation. Awoniyi (2015) aptly describes African cultural heritage as living traditions as well as precious wealth that need to be harnessed and tailored towards African development. This may have been the basis of the bond of unity, peace, friendship and good neighborliness as well as other very laudable socio-ethical virtues. It is also observable that the traditional cultural ethos and the ethical values and norms are highly intertwined.

It may then imply that ethical standards and values are informed and shaped by sociological standards. It may be important to state that the societal context of what is right and wrong or acceptable and unacceptable seems to vary from one geographical ecosystem to the other even within a confined geographical space. The sociological backgrounds of many African societies are based on deeply entrenched traditions handed down from ancestors and are expected to be handed to descendants yet unborn. An important aspect of traditional African education is concerned with teaching oral literature using folktales, riddles and proverbs which are aimed at molding character and providing children with moral values like honesty, integrity, hospitality, truth, respect for old age, covenant-keeping, hard work, good character courage and solidarity (Awoniyi, 2015; Sone, 2018). For example, traditional teachings on patriotism and the meanings giving to a person with a good character are for the person to love his/her people, kith and kin. Such a person should represent the community as an ambassador and defend the land to the extent of dying for the general good of the land. Gyekye (2011) in looking at ethics highlights the centrality of the notions of character and moral personhood as inspired by the African moral language. It is believed that exogenous ideas and practices of potential benefit to Africa must build from the inside out, not outside-in, as an imposition (Mulanga, 2014). However, if certain socio-ethical elements are inimical to society's progress then such socio-ethical elements are selfdestructive and can trigger the self-destructive work behaviors of employees.

Jollimore (2014) posits that morality requires one to be neutral and impartial. Molefe (2016), having closely observed the moral intuitions characteristic of African moral thought such as high prize usually accorded to the family, veneration of ancestors and the notion of personhood, argued that African ethics is best captured in terms of partiality. However controversial this might be, it may not be farfetched that all of these socioethical practices may have considerable influence on the fundamental fabric of behavior, especially at the workplace. This implies that a system that promotes partiality, favoritism or self-interest is seen as morally defective and if the guiding moral compass is defective then the emanating behavior will likely be selfdestructive. For example, the perceived inequity that emanates when ethnicity or any surface-level diversity 
is a basis for the selection of persons to be favored or disfavored adversely influences the way work is done as well as in the work behavior of employees. Again, due to the respect for traditional institutions, a manager may uncomfortable querying or reprimanding a community chief or a person of royalty should such a person err in the workplace. In the same vein, one societal expectation of a person occupying a position of authority is that during recruitment or the distribution of organizational favors such a person is expected to favor close in-group members before others irrespective of qualifications. Apart from the conflict of interest this might cause, in-group members feel they are privileged and above the law, as they are hardly reprimanded or at worst they get a slap on the wrist.

Societal-Level Self-Diagnosis and Therapy: The African socio-ethical space still has issues such as ethnic and religious bigotry, nepotism, reverence of the rich and powerful as well as social expectations of persons occupying certain positions or doing certain jobs among others that have not been development friendly. Socio-ethical foundations which are not self-destructive will help in building capacities in individuals and institutional processes to meet and exceed present-day requirements in the global space. Suffice it to say that the higher the societal expectation, the higher the tendency of persons to desire to engage in self-destructive work behaviors such as fraud, embezzlement, nepotism, tribalism as well as other forms of corruption. Selfrecognizable elements of societal self-destructive behaviors are based on situations and behaviors that are prevalent in society. Some of them include high levels of felt deprivation discrimination and powerlessness in situations where qualified persons are not given the opportunity to contribute to the society because of their unique identities and the in-group they belong to, greed, selfishness, insincerity, aversion to research and development for innovation, poorly envisioned plans and modus of implementation, decisions riddled and beclouded with ulterior motives.

All the aforementioned self-recognizable elements which have implications for socio-ethical foundations of workplace behaviors may just be the 'ants' destroying the commonwealth of Africa's 'kola nut' of sustainable socio-economic emancipation. Self-destructive behavior at the societal level should be taken as a collective mental condition, with an urgent need for collective therapy through community-driven reorientation programs. Traditional African values are based on many progressive socio-ethical attributes as well as very high ethical and moral foundations with work ethos hinged on hard work, dignity in labor, honesty, probity and integrity all of which are sources of pride and uniqueness world-others can learn from. This work assumes that the management praxis of the productive enterprises are based on highly native traditional socio-ethical foundations and this work calls for a renaissance, total rebirth and regeneration of the meanings given to the socio-ethical elements which transcend many workplaces. In line with this thought, it has been opined that there is a need to rethink management practice and leadership in Africa as well as theoretically upgrade philosophies such as Ubuntu as currently being theorized (Eyong, 2019; Guma, 2012). For instance, one can still be one's "brother's keeper" only if there is a redefinition of brotherhood to include persons living in the same world.

As one human race without recourse to genetics, race, ethnicity or any other in-group relationship; one can still be selfless for the good of everyone. The African socio-economic landscape has not improved significantly. Imagine that if everyone does good for the good of everyone else, then there will be enough good to go around for the good of all: National decisions should be based on their socio-economic imperatives and should neither arouse sentiments and suspicions nor be for selfish and personal gains; ventures set up should have all the necessary plans for funding, provision of basic structures and infrastructure such as power supply, water supply roads, transportation and even the manpower with the right qualification to run them; redefine the Societal values placed on financial status as a measuring yardstick for success without which persons in workplaces may become highly bothered about their earnings thereby increasing the likelihood of engaging in shady practices. Planning should be properly envisioned, especially in the long term and strategically implemented to reduce the somewhat haphazard way things are sometimes done; bottlenecks that stand in the way of ease of doing business should be eliminated at all costs. Create structures and means of identifying, sponsoring or encouraging unique skills and talents as well as make budgetary allocations for research and development, where innovation will be encouraged.

Socioeconomic Emancipation: To highlight how the management of self-destructive work behavior could add value to national wellbeing, the concept of socio-economic emancipation is briefly conceptualized. Socio- 
economic emancipation of Africa in this work is seen as the extent to which the aggregate productive capacity status of firms in an economy is able to compete favorably in the global space and positively affect the general wellbeing and outlook of the populace alongside the flora and fauna. The greater the extent the aforesaid feat is achieved, the higher the status of Socio-economic emancipation, and vice versa. The assumption is that a proper self-destructive work behavior management will have positive effects on a firms' product/service quality and quantity, level of innovation as well as the level of accessibility of firms' products/services to the end-user all of which are the measures of the productive capacity status of firms in an economy. With all these properly done through proper self-destructive work behavior management, the much desired socioeconomic emancipation will be achieved and the continent will meet and surpass whatever SDGs there are. If this is achieved, Africa will not only have carved a niche for herself but will set strategic new world standards for others to follow.

\section{Conclusion and Recommendations}

Africa has highly progressive socio-ethical ancestral injunctions but that over time, the genuine desires and intentions of such injunctions may have been eroded and adversely distorted to the detriment of contemporary workplaces. These observable socio-ethical praxes, which seem ingrained and as part of the ancestral heritage, stem from the individuals, firms' processes and the society. All of these distortions which have implications for socio-ethical foundations of work behavior may just be the 'ants' destroying the commonwealth of Africa's 'kola nut' of sustainable socio-economic emancipation. Thus, it could be safe to assume that negatively distorted socio-ethical work behaviors, as being currently exhibited in many work settings in Africa may be the cause of the myriads of multiple challenges bewitching the productive capacities of the continent of Africa and preventing her from achieving the very much desired sustainable socioeconomic emancipation. The firms in Africa cannot continue to do the same thing in the same way and expect different results. Based on the theoretical assumption in the foregoing, the most important policy implication is that therapy is an efficacious intervention to self-destructive behaviors. It becomes imperative, for individuals, corporate entity managers, managers of the wellbeing of society and other concerned stakeholders who are in desperate need of socio-economic emancipation of the African continent, to Manage Self-Destructive Work Behaviors through the multi-level simultaneous self-diagnosis and therapy process as highlighted in this paper.

Acknowledgment: I sincerely appreciate the extensive comments and suggestions of Bella L. Galperin to unedited manuscript.

\section{References}

Akugri, M. S., Bagah, D. A. \& Wulifan, J. K. (2015). The contributions of small and medium scale enterprises to economic growth: A cross-sectional study of zebilla in the Bawku West district of Northern Ghana. European Journal of Business and Management, 7(9), 262-274.

Aloko, S. M. A. \& Usman, A. (2018). Corruption and underdevelopment in Nigeria: Challenges and solutions. Scientific Research Journal (SCIRJ), 6(XI), 1-10.

Amadi, L. \& Ekekwe, E. (2014). Corruption and development administration in Africa: Institutional approach. African Journal of Political Science and International Relations, 8(6), 163-174.

Atta-Mensah, J., Tang, V. T. \& Shaw, T. M. (2019). Towards economic transformation: The way forward for Africa. In Development and Sustainable Growth of Mauritius (239-51). New York, Palgrave: MacMillan.

Awoniyi, S. (2015). African cultural values: The past, present and future. Journal of Sustainable Development in Africa, 17(1), 1-13.

Barratt, E. S. (1994). Impulsiveness and aggression. In J. Monahan \& H. J. Steadman (Eds.), The John D. and Catherine T. MacArthur Foundation series on mental health and development. Violence and mental disorder: Developments in risk assessment (p. 61-79). Chicago, IL: The University of Chicago Press.

Besada, H. G. (Ed). (2016). Governing natural resources for Africa's development. New York, NY: Routledge.

Butcher, J., Mineka, S. \& Hooley, J. (2007). Abnormal Psychology and Modern Life (13th Ed). Boston, MA: Allyn \& Bacon.

Dauda, M., Ahmad, M. Z. B. \& Keling, M. F. (2019). Hegemony and leadership in Africa: An appraisal of Nigeria's role. Asian People Journal, 2(1), 138-154. 
Ejiaku, S. A. (2014). Technology adoption: Issues and challenges in information technology adoption in emerging economies. Journal of International Technology and Information Management, 23(2), 29-68.

Eyong, J. E. (2019). Leadership for high performance in local councils in Cameroon and Nigeria: Examining deviant and concordant practices to the philosophy of Ubuntu. Africa Journal of Management, 5(2), 138-161.

Guma, P. K. (2012). Rethinking management in Africa: Beyond Ubuntu. Rochester.

Gyekye, K. (2011). African Ethics. The Stanford Encyclopedia of Philosophy. Edward N. Zalta (ed.), URL = $<$ https://plato.stanford.edu/archives/fall2011/entries/african-ethics/>.

Hanson, K. T. (2017). Managing Africa's natural resource endowments: New dispensations and good-fit approaches. Journal of Sustainable Development Law and Policy, 8(1), 121.

Herpertz, S., Sass, H. \& Favazza, A. B. (1997). Impulsivity in self-mutilative behavior: Psychometric and biological findings. Journal of Psychiatric Research, 31(4), 451-465.

Jutel, A. (2019). Diagnosis: A critical social reflection in the genomic era. Ciencia \& saude coletiva, 24(10), 3619-3626. https://doi.org/10.1590/1413-812320182410.34502018

Jollimore, T. (2014). Impartiality. The Stanford Encyclopedia of Philosophy. Edited by E.N. Zalta. http://plato.stanford.edu/archives/sum2011/entries/impartiality/ (accessed on 27 May 2020).

Mlambo, D. N., Mubecua, M. A., Mpanza, S. E. \& Mlambo, V. H. (2019). Corruption and its implications for development and good governance: A perspective from post-colonial Africa. Journal of Economics and Behavioural Studies, 11(1), 39-47.

Molefe, M. (2016). African Ethics and Partiality. Phronimon, 17(2), 1-19.

Mulanga, C. (2014). Identifying and understanding African norms and values that support endogenous development in Africa. Journal Development in Practice, 24(5-6), 623-636.

Muritala, T. A., Taiwo, A., Awolaja, A. M. \& Bako, Y. A. (2012). Impact of small and medium enterprises on economic growth and development. American Journal of Business and Management, 1(1), 18-22.

Ndizera, V. \& Muzee, H. (2018). A critical review of Agenda 2063: Business as usual? African Journal of Political Science and International Relations Review, 12(8), 142-154.

NIDA. (2018). Understanding Drug Use and Addiction Drug Facts. Retrieved from https://www.drugabuse.gov/publications/drugfacts/understanding-drug-use-addiction on 2020, October 21.

Odemba, A. S. (2012). Corruption in Sub-Saharan Africa: A phenomenological study. Journal of Psychological Issues in Organizational Culture, 3(1), 21-40.

Rakel, R. E. (2018). Diagnosis. Encyclopedia Britannica. https://www.britannica.com/science/diagnosis Access Date October 28, 2020.

Seck, P. A., Agboh-Noameshie, A., Diagne, A. \& Bamba, I. (2013). Repackaging agricultural research for greater impact on agricultural growth in Africa. Journal of Food Security, 1(2), 30-41.

Singer, P. (2020). Ethics. Encyclopedia Britannica, https://www.britannica.com/topic/ethics-philosophy Access Date October 24, 2020.

Sone, E. M. (2018). The folktale and social values in traditional Africa. Eastern African Literary and Cultural Studies, 4(2), 142-159.

Sroka, W. \& Lorinczy, M. (2015). The perception of ethics in business: Analysis of research results. Procedia Economics and Finance, 34, 156-163.

Tsirigotis, K. (2018). Indirect self-destructiveness in individuals with schizophrenia. Brazilian Journal of Psychiatry, 40(1), 41-47.

Ugwuzor, M. (2018). Repackaging employee behavior for national development in Nigeria. Journal of Management Sciences, 3(1), 155-162.

United Nations. (2015). Resolution adopted by the General Assembly on 25 September 2015, Transforming our world: The 2030 Agenda for sustainable development (A/RES/70/1).

Wiid, J. A., Cant, M. C. \& Niekerk, C. V. (2013). Moral behavior and ethical misconduct in Nigerian Small Businesses. International Business \& Economics Research Journal, 12(9), 1087-1100.

Wykes, T. \& Callard, F. (2010). Diagnosis, diagnosis, diagnosis: Towards DSM-5. Journal of Mental Health, 9(4), 301-304.

Zerihun, M. F., Breitenbach, M. \& Kemegue, F. (2015). The way forward on African Economic Integration Initiatives: Evidence from Southern African Development Community. Conference Paper presented at the Biennial Conference of the Economic Society of South Africa at the University of Cape Town, Cape Town, South Africa. 